\title{
CONSTRUÇÕES EM ÁREAS DE PRESERVAÇÃO PERMANENTE E 0 CONFLITO ENTRE DIREITOS FUNDAMENTAIS
}

\section{BUILDINGS IN PERMANENT PRESERVATION AREAS AND THE CONFLICT BETWEEN FUNDAMENTAL RIGHTS}

\author{
TATIÉLE CARDOSO MONTEIRO \\ Acadêmica do Curso de Direito Noturno da Universidade Federal de Santa Maria
}

\begin{abstract}
RESUMO
O presente trabalho apresentará um breve estudo acerca do embate existente entre o direito de construir, como corolário do direito de propriedade, e o direito ao meio ambiente ecologicamente equilibrado, no que se refere às áreas de preservação permanente. A partir de uma análise feita através de critérios dedutivos, genericamente, destacar-se-ão alguns conceitos atinentes à matéria em relevo, bem como as previsões legais e constitucionais para ambos os direitos em comento, com o escopo de analisar a importância da preservação de tais áreas frente ao crescimento desenfreado das cidades. Por fim, demonstrar-se-á que as áreas de preservação permanente se prestam a limitar o direito de construir, buscando-se verificar o direito prevalente em casos de perpetuação de construções em tais espaços, através da utilização do método da ponderação e da relevância do interesse analisado. A partir disso, preliminarmente, se concluirá que, casuidicamente, o direito de construir poderá ser fundamentadamente autorizado nas áreas de preservação permanente.
\end{abstract}

Palavras-chave: áreas de preservação permanente; direito ao meio ambiente ecologicamente equilibrado; direito de construir; direitos fundamentais.

\begin{abstract}
The present work will present a brief study of the clash between the right to build, as a corollary of the right to property, and the right to an ecologically balanced environment, with regard to areas of permanent preservation. As from an analysis using deductive criteria, generally, will be highlighting some concepts relating to the matters raised, as well as forecasts for both legal and constitutional rights under discussion, with the aim of analyzing the importance of preserving such areas against the rampant growth of cities. Finally, it will demonstrate that the permanent preservation lend themselves to limit the right of building, trying to find the prevalent right in cases of perpetuation of buildings in such spaces, through the method of weighting and through the relevance of the analyzed interest. From that, preliminarily, will conclude that, in certain cases, the right to build can reasonably be allowed in areas of permanent preservation.
\end{abstract}

Keywords: fundamental rights; permanent preservation areas; right to an ecologically balanced environment; right to build.

\section{SUMÁRIO}

INTRODUÇAO; 1 O DIREITO DE CONSTRUIR E O DIREITO AO MEIO AMBIENTE ECOLOGICAMENTE EQUILIBRADO: PREVISÕES LEGAIS; 1.1 Direito de Construir e Direito ao Meio Ambiente Ecologicamente Equilibrado: proteção constitucional e infraconstitucional; 1.2 Função Socioambiental das Construções Urbanas: o direito de construir sob o viés da manutenção do equilíbrio ecológico; 2 Construções em Áreas de Preservação Permanente: O CONFLITO DE DIREITOS E O USO DO CRITÉRIO DA PONDERAÇÃO PARA SOLUCIONÁ-LO; 2.1 As Áreas de Preservação Permanente como Limitação ao Direito de Construir; 2.2 Direitos Fundamentais em Conflito: a ponderação como uma proposta para solucionar tal embate; CONCLUSÃO; REFERÊNCIAS. 


\section{INTRODUÇÃO}

A indústria da construção civil, como se sabe, tem experimentado um crescimento interessante, servindo, em dada escala, ao incremento do desenvolvimento econômico do país. Conforme dados do IBGE, a partir do ano de 2004 resultados expressivos passaram a ser observados, havendo um crescimento da construção nacional, até o ano de 2010, no patamar de 42,41\%. Ademais, forte nos dados divulgados pelo órgão supramencionado, o PIB (Produto Interno Bruto) da construção civil, no ano de 2012, correspondeu a 5,3\% do PIB Nacional, isto é, consolidou-se no montante aproximado de 165 bilhões de reais, marco recorde até então, o que demonstra a real importância deste setor para a economia do Brasil ${ }^{1}$.

Nesse diapasão, tendo em vista a aceleração do setor da construção civil e a urbanização desenfreada experimentada pela população brasileira, o desenvolvimento das cidades tem sido comumente fruto de diversas polêmicas envolvendo, inclusive, outra pauta bastante relevante hoje em dia, qual seja o meio ambiente. Observa-se que, muitas vezes, seja pela estrutura logística inadequada oferecida a determinadas parcelas da população, que não gozam de serviços básicos de saneamento, por exemplo, seja por outros fatores que não cabe aqui referir, uma questão bastante relevante, no que se refere às ocupações urbanas é, justamente, as construções, sejam elas de pouca ou alta monta financeira, em áreas de preservação permanente.

Há que se destacar que todos os cidadãos gozam do direito de propriedade e, ínsito neste direito, encontra-se o direito de construir, portanto, nas áreas urbanas. Todavia, assim como de um lado a Constituição Federal salvaguarda o referido direito, a Carta Magna, de outro, resguarda o direito que todos tem, também, ao meio ambiente ecologicamente equilibrado. É justamente neste ponto que emerge a questão relativa às áreas de preservação permanente, vez que protegidas pelo legislador, em função de sua importância ecológica, muitas vezes são palco de construções irregulares.

\footnotetext{
${ }^{1}$ Há que se destacar que no ano de 2011 os números não foram tão expressivos, demonstrando que se está chegando a um momento de equilíbrio para o setor da construção civil. Todavia, tal fato não representa estagnação do setor em comento, mas sim, nos termos do que foi divulgado pela CBIC - Câmara Brasileira da Indústria da Construção, "o ano 2011 caracterizou-se por um processo natural de acomodação das atividades, buscando o ponto de equilíbrio sustentável do crescimento setorial.".
} 
Tendo em vista, assim, o aparente conflito entre normas de natureza constitucional, surge na realidade jurídica uma celeuma: o direito de construir, como corolário do direito constitucional de propriedade, pode se sobrepor ao direito ao meio ambiente ecologicamente equilibrado? Subsiste, assim, a possibilidade de um direito individual se justapor a um direito coletivo, de natureza transindividual?

No presente trabalho, portanto, sem o escopo de esgotar o tema, através de uma pesquisa de natureza basicamente teórica, respaldada na legislação e na doutrina nacionais e perpetrada através de um método dedutivo, buscar-se-á, primeiramente, analisar os aspectos legais atinentes tanto ao direito de propriedade e, em paralelo, ao direito de construir, bem como àqueles que dizem respeito ao direito ao meio ambiente ecologicamente equilibrado (parte 1.1), buscando destacar o caráter de direito fundamental que ambas apresentam. Por fim, abordar-se-á, de forma genérica, acerca da função socioambiental inerente à propriedade, intentando-se analisar quais foram as reais intenções do legislador ao alçar o tal direito ao patamar constitucional (parte 1.2).

Em um segundo momento, também com algum embasamento teórico, analisar-se-á a questão a que se dedica este trabalho, abordando, genericamente, o conceito atinente às áreas de preservação permanente e trazendo a lume, inicialmente, a ideia de que tais espaços se prestam a limitar o direito de construir (parte 2.1). Por fim, uma vez levantada a discussão referente ao aparente embate existente entre o direito de construir e o direito ao meio ambiente ecologicamente equilibrado, no que tange, em específico, as áreas de preservação permanente, buscar-se-á analisar tal questão sob o prisma do critério da ponderação, de forma a averiguar se, em casos tais, subsiste a possibilidade de supressão de um direito em prol da efetivação de outro (parte 2.2).

\section{DIREITO DE CONSTRUIR E O DIREITO AO MEIO AMBIENTE ECOLOGICAMENTE EQUILIBRADO: PREVISÕES LEGAIS}

A propriedade privada ${ }^{2}$ possui, na esteira do que preconizam os artigos $5^{\circ}$, incisos XXII e XXIII e 170, inciso $~ I I^{3}$, da Carta Magna, status constitucional. Nesse talante, ao proprietário de

${ }^{2}$ Conforme prelecionam Cristiano Farias e Nelson Rosenvald, no que tange à conceituação do instituto em apreço, "a propriedade é um direito complexo, que se instrumentaliza pelo domínio, possibilitando ao seu titular o exercício de um feixe de atributos consubstanciados nas faculdades de usar, gozar, dispor $e$ 
um bem, estão garantidas todas as faculdades de domínio inerentes à propriedade privada listadas no caput, do artigo 1.228, do Código Civil, quais sejam, as faculdades de usar, gozar, dispor e de reivindicá-lo. Conforme preceitua Cristiano Farias e Nelson Rosenvald ${ }^{4}$, tais faculdades “não são poderes autônomos, mas poderes ínsitos à situação proprietária”.

Nesta senda, tendo o proprietário do bem o direito a utilizar a coisa como bem lhe aprouver, tirando dela os benefícios que entender necessários e satisfatórios, desde que respeitados os direitos de terceiros, há que se reconhecer o direito que os donos de bens imóveis possuem de construir. 0 direito de construir ${ }^{5}$, portanto, consubstancia-se em corolário do direito de propriedade. Aquele que for proprietário de um terreno tem, assegurado constitucionalmente, o direito de usar, gozar, dispor e de reivindicá-lo, acaso necessário.

Todavia, impende ressaltar que tal direito, de cunho individual, deve se submeter, por exemplo, a limitações de ordem ambiental, devendo ser respeitado outro direito constitucionalmente tutelado, porém, de cunho coletivo: o direito ao meio ambiente ecologicamente equilibrado, preconizado no artigo 225, caput, da Carta Magna ${ }^{6}$. 0 direito em liça, conforme se verá, ao contrário do direito de propriedade, está envolto de um caráter solidário, haja vista fazer parte da esfera jurídica de todos os cidadãos.

reivindicar a coisa que the serve de objeto (...). O direito subjetivo de propriedade concerne à relação jurídica complexa que se forma entre aquele que detém a titularidade formal do bem (proprietário) e a coletividade de pessoas. Nos bens imóveis, nasce a propriedade através do ato de registro, que a tornará pública e exigível perante a sociedade.".

${ }^{3}$ Art. $5^{\circ}$. Todos são iguais perante a lei, sem distinção de qualquer natureza, garantindo-se aos brasileiros e aos estrangeiros residentes no País a inviolabilidade do direito à vida, à liberdade, à igualdade, à segurança e à propriedade, nos termos seguintes:

$(\ldots)$

XXII - é garantido o direito de propriedade;

XXIII - a propriedade atenderá a sua função social;

Art. 170. A ordem econômica, fundada na valorização do trabalho humano e na livre iniciativa, tem por fim assegurar a todos existência digna, conforme os ditames da justiça social, observados os seguintes princípios:

(...)

II - propriedade privada;

${ }^{4}$ FARIAS, Cristiano Chaves de; ROSENVALD, Nelson. Direitos Reais. 7. ed. Rio de Janeiro: Lumen Juris, 2011.

${ }^{5} \mathrm{O}$ Direito de Construir, em linhas gerais, na esteira do que alude Siqueira (2012, p. 108), refere-se ao "direito à proteção da relação de um sujeito sobre uma edificação, cujo objeto possui as mesmas limitações ou restrições referentes à propriedade privada". Nesta senda, tratar-se-á o tema apresentando as limitações administrativas e legais da propriedade privada como atinentes, em consequência lógica, ao direito de construir.

${ }^{6}$ Art. 225. Todos têm direito ao meio ambiente ecologicamente equilibrado, bem de uso comum do povo e essencial à sadia qualidade de vida, impondo-se ao Poder Público e à coletividade o dever de defendê-lo e preservá- lo para as presentes e futuras gerações. 
Há, assim, inicialmente, que se analisar os aspectos legais relativos a cada um dos referidos direitos, tecendo-se algumas considerações pontuais acerca do direito de propriedade, do direito de construir, da função social que este último visa a conferir à propriedade privada e, por fim, do direito ao meio ambiente ecologicamente equilibrado, salientando-se seus aspectos legais e a necessidade de que sejam exercidos de forma harmônica e sustentável (parte 1.1). Na sequência, de forma a corroborar a ideia de que o exercício do direito de propriedade coadunase com princípios de direito ambiental, analisar-se-á a exigência constitucional do cumprimento de sua função ambiental, em especial, aquela relativa às construções urbanas, observando-se, a partir daí, uma mudança no caráter individualista da propriedade privada (parte 1.2).

\subsection{Direito de Construir e Direito ao Meio Ambiente Ecologicamente Equilibrado: proteção constitucional e infraconstitucional}

O Direito de Construir está ínsito no Direito de Propriedade. Neste sentido, cumpre destacar as ilações de Hely Lopes Meirelles, em sua obra Direito de Construir:

O fundamento do direito de construir está no direito de propriedade. Desde que se reconhece ao proprietário o poder legal de usar, gozar e dispor dos seus bens (Código Civil, art. 1.228), reconhecido está o direito de construir, visto que no uso, gozo e disponibilidade da coisa se compreende a faculdade de transformála, edificá-la, beneficiá-la, enfim, com todas as obras que the favoreçam a utilização ou the aumentem o poder econômico ${ }^{7}$.

Primeiramente, impõe-se referir que a propriedade privada, na esteira do que já foi aduzido linhas acima, foi alçada pelo legislador constituinte à categoria de direito constitucional. $O$ artigo $5^{\circ}$ da Constituição Federal, tratando dos direitos e garantias fundamentais dos cidadãos, preconizou que a propriedade privada deve ser igualmente assegurada a todos os indivíduos. Em seus incisos XXII e XXIII, o constituinte originário, garantiu a todos os cidadãos, em igualdade de condições, o direito de propriedade.

Entretanto, há que se fazer uma ressalva: tal direito, em decorrência da própria previsão constitucional em supramencionada, deverá ser exercido de forma a efetivar a função social desta propriedade, isto é, impõe a Lei Maior o dever a todos os indivíduos de dar uma

${ }^{7}$ MEIRELLES, Hely Lopes. Direito de Construir. 10. ed. São Paulo: Malheiros, 2011, p. 30. 
destinação adequada ao bem do qual se faz proprietário ${ }^{8}$. De forma, nesta senda, a definir 0 conteúdo da supramencionada função social da propriedade urbana, sobreveio o artigo 182, § $2^{\circ}$, do mesmo Diploma Legal, preconizando os requisitos necessários para que o proprietário cumpra com tal exigência?.

Nesse diapasão, o que se verifica é que a faculdade de edificar, como consequência direta das faculdades inerentes à propriedade privada, possibilita ao proprietário, de uma forma específica, cumprir com a função social do bem a que detém o domínio. Não há que se discutir, por ora, se a vantagem auferida será de cunho individual ou coletivo, mas somente que, na esteira das previsões legais que dizem respeito à necessidade de dar ao bem uma adequada e efetiva destinação, o direito de construir é um meio para o implemento de tal exigência.

Não diferentemente o Código Civil Brasileiro lidou com a questão. Conforme o $\S 1^{\circ}$, do artigo 1.228, do Diploma Legal mencionado, a propriedade privada deverá ser exercida em consonância com exigências legais de destinação social e econômica do bem, havendo de serem respeitados os limites de uso, gozo e disponibilidade que vierem a ferir a incolumidade ambiental e o patrimônio histórico e cultural ${ }^{10}$. Ao que se depreende, portanto, a despeito de ser outorgado ao proprietário, como regra, a liberdade de usufruir e explorar sua propriedade, de forma a implementar sua função social, tal direito encontra-se restringido por um direito difuso, de mesma natureza: o direito ao meio ambiente ecologicamente equilibrado ${ }^{11}$.

\footnotetext{
${ }^{8}$ No Capítulo I, do Título VII, tratando da Ordem Financeira e Tributária, traz a Magna Carta os princípios gerais que devem reger a atividade econômica do país, aludindo nos incisos II e III, do artigo 170, como tais, a propriedade privada e a função social da propriedade, o que demonstra a importância a que alçou o legislador constituinte não somente ao direito de ser proprietário, mas também, de cumprir com a função social daquilo a que se detém o domínio, relevando a conotação econômica e social que também possui tal instituto.

${ }^{9} \mathrm{O}$ artigo referido determina o seguinte:

Art. 182. A política de desenvolvimento urbano, executada pelo Poder Público municipal, conforme diretrizes gerais fixadas em lei, tem por objetivo ordenar o pleno desenvolvimento das funções sociais da cidade e garantir o bem- estar de seus habitantes.

(...)

$\S 2^{\circ}$ - A propriedade urbana cumpre sua função social quando atende às exigências fundamentais de ordenação da cidade expressas no plano diretor.

${ }^{10}$ Art. 1.228. O proprietário tem a faculdade de usar, gozar e dispor da coisa, e o direito de reavê-la do poder de quem quer que injustamente a possua ou detenha.

$\S 1^{\circ} \mathrm{O}$ direito de propriedade deve ser exercido em consonância com as suas finalidades econômicas e sociais e de modo que sejam preservados, de conformidade com o estabelecido em lei especial, a flora, a fauna, as belezas naturais, o equilíbrio ecológico e o patrimônio histórico e artístico, bem como evitada a poluição do ar e das águas.

11 O conceito de meio ambiente ecologicamente equilibrado, entende-se, no presente trabalho, como aquele correspondente a todo e qualquer espaço: urbano, cultural, ecológico, de trabalho, etc.
} 
Importa, neste norte, aludir que o direito ambiental em comento está envolto de um caráter prementemente solidário, cabendo a todos os indivíduos, de forma indeterminada, gozarem de tal prerrogativa. A partir daí, o direito individual de propriedade passa a assumir contornos, também, mais sociais, vez que a sua efetivação depende da adequação de seu exercício aos ditames de ordem ambiental.

Assim, em que pese o direito de construir, como corolário lógico do direito de propriedade e instrumento para efetivação da função social da propriedade, determinada tanto pelo Código Civil quanto pela Constituição Federal, estar alçado à categoria de direito fundamental, seu exercício encontra-se, desde já, limitado pelo direito ao meio ambiente ecologicamente equilibrado, a que todos os cidadãos, igualmente, tem direito ${ }^{12}$. Neste sentido, importa concluir, preliminarmente, que, a despeito de, em regra, ser o exercício do direito de propriedade livre a todos os indivíduos, o direito ao meio ambiente equilibrado, que da mesma forma atine a toda a coletividade, entrava, em certa medida, o uso desmedido e irracional da propriedade $^{13}$.

Nesta senda, apressadamente, observa-se que o direito ao meio ambiente equilibrado, saudável e sustentável, ocupa posição hierárquica equivalente àquela ocupada pelo direito de propriedade. A despeito de tratar-se de direitos de cunho, inicialmente, díspares (individual e difuso), ambos ocupam o patamar de direitos fundamentais e, portanto, são constitucionalmente assegurados a todos os indivíduos, sendo justamente de tal contraponto que deflui a celeuma jurídica a respeito de qual dos direitos em confronto deve prevalecer na prática.

Assim, de forma a propiciar a construção de inferências relativas a tal imbróglio, necessário tecer algumas ponderações acerca da função socioambiental das construções urbanas, como forma de reforçar a ideia de que a índole individualista do direito de propriedade vem sendo relativizada.

\footnotetext{
${ }^{12}$ Neste sentido, o artigo 225, da Constituição Federal.

${ }^{13} \mathrm{O}$ direito ao meio ambiente equilibrado e sustentável, entende-se, encontra-se no mesmo patamar do direito de propriedade, isto é, também foi relevado pelo legislador constituinte como um direito fundamental. Contudo, diferentemente do mencionado direito de propriedade, o direito em apreço toma formas de um direito de natureza difusa, vez que deve ser assegurado a toda a coletividade de forma indeterminada. Todos os indivíduos tem direito a viver em um meio ambiente saudável. Não se trata, portanto, de um direito de poucas pessoas ou de uma categoria de pessoas, mas sim, de um direito inerente a todos os cidadãos.
} 


\subsection{Função Socioambiental das Construções Urbanas: o direito de construir sob o viés da manutenção do equilíbrio ecológico}

$\mathrm{Na}$ esteira do que foi destacado nas linhas precedentes, afere-se que tanto o direito de propriedade quanto o direito ao meio ambiente ecologicamente equilibrado fazem parte da esfera jurídica de todos os cidadãos, no patamar de direitos fundamentais. Contudo, em que pese tal característica, o primeiro possui um cunho mais individualista, referindo-se ao direito que cada um tem de exercer seus direitos sobre a sua própria propriedade e o segundo, uma vez que atine a uma quantidade indeterminada de pessoas, encontra-se envolto de caráter difuso, transindividual.

Diferem, portanto, tais direitos nestes aspectos. Todavia, consoante já se referiu alhures, guarnecida pela exigência de que efetivamente cumpra com sua função social, a propriedade privada, com o advento da Constituição Federal de 1988, passou a apresentar não mais somente características de ordem individual, mas também, de ordem social e coletivista. Relativizou-se, assim, o conceito estanque de propriedade privada, cujo principal escopo era garantir ao seu proprietário vantagem econômica: uma vez que o exercício de tal direito somente pode se dar em atendimento a sua função social, limita-se o uso descabido da propriedade privada.

Outrossim, há que se referir que a Lei Maior impregnou a propriedade privada de uma outra imprescindível função: a função ambiental. 0 já referido artigo 225 , da Constituição Federal, no inciso III, do $\S 1^{\circ}$, estabelece a necessidade de o Poder Público delimitar as áreas que necessitem de proteção especial, vedando a sua exploração e a realização de atividades que exponham as espécies biológicas aos riscos da extinção ${ }^{14}$. Neste diapasão, instrumentalizou também a coletividade a adotar condutas condizentes com a preservação do meio ambiente e a manutenção do equilíbrio ecológico.

\footnotetext{
${ }^{14}$ Art. 225. Todos têm direito ao meio ambiente ecologicamente equilibrado, bem de uso comum do povo e essencial à sadia qualidade de vida, impondo-se ao Poder Público e à coletividade o dever de defendê-lo e preservá- lo para as presentes e futuras gerações.

$\S 1^{\circ}$ - Para assegurar a efetividade desse direito, incumbe ao Poder Público:

(...)

III - definir, em todas as unidades da Federação, espaços territoriais e seus componentes a serem especialmente protegidos, sendo a alteração e a supressão permitidas somente através de lei, vedada qualquer utilização que comprometa a integridade dos atributos que justifiquem sua proteção; (Regulamento)
} 
A Ordem Econômica e Financeira, na qual se fundamenta o Estado Brasileiro, possui moldes capitalistas, mas, em contraposição, possui um caráter essencialmente social, vez que trouxe no bojo do artigo 170, inciso VI, previsão específica no que se refere à “defesa do meio ambiente, inclusive mediante tratamento diferenciado conforme o impacto ambiental dos produtos e serviços e de seus processos de elaboração e prestação", como um dos princípios a serem atendidos na busca pelo desenvolvimento econômico do país. Desta banda, o que se infere é que a proteção do meio ambiente foi tratada pela Carta Magna como um princípio imprescindível à concretização de outros princípios sociais por ela salvaguardados. Um deles é o princípio da Dignidade da Pessoa Humana, visto que a qualidade de vida e a saúde dos cidadãos dependem, em grande parte, de um meio ambiente equilibrado e saudável.

Nesse talante, alinhavam-se os preceitos constitucionais de defesa do meio ambiente e do direito ao meio ambiente ecologicamente equilibrado, citados alhures, ao implemento do direito de propriedade inerente aos cidadãos, vez que, a partir destas previsões legislativas não há mais que se falar em um direito particular envolto de cunho exclusivamente individual, mas também em um direito prementemente social e ambiental. Ora, observa-se que o Diploma Civil Brasileiro não se desvinculou, em nenhum momento, de tal preceito, garantindo ao proprietário todos os direitos e faculdades inerentes à coisa, desde que exercidos em consonância com os ditames da preservação ambiental ${ }^{15}$.

Emerge no ordenamento jurídico, assim, uma limitação de ordem principiológica ao direito de propriedade de cunho essencialmente ambiental, isto é, a liberdade individual de desfrutar da propriedade privada encontra-se entravada pelo direito coletivo ao meio ambiente ecologicamente equilibrado. Prima, portanto, a Constituição Federal pela proteção do meio ambiente, devendo o proprietário não somente efetivar a função social de seu bem, mas também, intrinsicamente conectada a tal exigência, implementar o uso consciente e ambientalmente adequado do mesmo para a manutenção do equilíbrio ecológico.

${ }^{15}$ Art. 1.228, § $1^{\circ}$, do Código Civil.

Observa-se, a partir da leitura do artigo 1.228 , $\S 1^{\circ}$, do Diploma Civil Brasileiro, que a propriedade, a partir da ótica da necessidade de se garantir a proteção ao meio ambiente, passa a apresentar uma percepção mais solidária do tratamento a ser dispensado ao instituto. Há uma maior preocupação por parte do Poder Legislativo em desconstruir o ideal individualista que circunda a propriedade privada, havendo que voltar às atenções à coletividade, que é a "proprietária" deste meio ambiente. Neste sentido, o direito de construir, como corolário lógico do direito de propriedade, também se encontra envolto pelo caráter social e pelo manto difuso que rege o direito ambiental. Assim, as construções devem ser procedidas de maneira sustentável, atenta às limitações ambientais e em consonância com o adequado manejo dos recursos naturais, incorporando, por conseguinte, ao ius edificandi a função socioambiental inerente ao Direito de Propriedade. 
Como consequência óbvia, as construções a serem implementadas na propriedade hão de ser consonantes com as regras de proteção ambiental, devendo adequar-se aos limites legais e urbanísticos impostos $^{16}$. Tudo isso, com o claro desiderato de vincular o exercício de tal direito à concretização do princípio da solidariedade, do qual goza o direito ambiental.

Nesta banda, o direito de construir vê-se, por oras, constrangido ante a exigência em epígrafe, vez que, se a despeito de estar envolto pelo manto constitucional de direito fundamental deve ser exercido de forma tutelar ao meio ambiente, nos casos das áreas especialmente protegidas pelo ordenamento jurídico, a limitação em questão, em um primeiro momento, aparenta-se intransponível, havendo, supostamente, o cerceamento de um direito fundamental.

\section{CONSTRUÇÕES EM ÁREAS DE PRESERVAÇÃO PERMANENTE: O CONFLITO DE DIREITOS E O USO DO CRITÉRIO DA PONDERAÇÃO PARA SOLUCIONÁ-LO}

Ao que se verifica, a aceleração do desenvolvimento econômico do país tem contribuído para a desenfreada urbanização das cidades. Sendo assim, a cada dia experimenta-se a ocupação de áreas territoriais diversas, no âmbito urbano. A necessidade de implementar a função social e ambiental da propriedade, assim, dá azo ao incremento da indústria da construção civil. Todavia, em que pese o direito de construir tratar-se de uma faculdade do direito de propriedade, não se pode olvidar que se encontra toda a coletividade dividindo um mesmo espaço e, portanto, este deverá ser preservado e manejado de forma sustentável e ambientalmente adequada.

Atento, por conseguinte, à necessidade de preservar o meio ambiente às futuras gerações, bem como garantir àquelas que, por ora, usufruem dos recursos naturais um espaço ambientalmente saudável, o legislador constitucional e infraconstitucional determinou que aquelas áreas que apresentassem maiores riscos de exaustão dos recursos, carecendo, assim, da estipulação de normas específicas de preservação, fossem especialmente tuteladas.

\footnotetext{
${ }^{16}$ Nas zonas urbanas, em específico, tais limitações ditadas pelo Poder Público como forma de efetivar a função socioambiental da propriedade privada, preconizadas nos artigos 182 e 183, da Constituição Federal, foram regulamentadas pela Lei 10.257/01 (Estatuto das Cidades), pelo Plano Diretor dos Municípios e, também, pela Lei de Uso e Parcelamento do Solo Urbano, dentre outros diplomas legislativos.
} 
As áreas de preservação permanente (APP), portanto, são espaços territoriais especialmente protegidos pelo ordenamento jurídico ${ }^{17}$. O Código Florestal de 1965, antes mesmo da promulgação da Carta Magna de 1988, já trazia em seu texto a necessidade de salvaguardar tais espaços da atuação humana predatória. Reforçada pela Constituição a premente necessidade de resguardar as áreas em comento, face à importância ecológica que detém, não se pode questionar da sua relevância para a manutenção do equilíbrio ambiental.

Entretanto, conforme se referiu alhures, tendo em vista a urbanização das cidades, muitas vezes, emergem conflitos jurídicos atinentes à propriedade privada de tais espaços e a interferência no direito de usar, gozar e de dispor das áreas em comento, sob o prisma da necessidade de preservá-las.

Nesse talante, em considerando a importância ecológica de tais áreas e a propriedade privada como um direito constitucional, primeiramente, intentar-se-á demonstrar as limitações ao direito de construir ditadas pela legislação e pelo Poder Público, no que tange às áreas de preservação permanente localizadas em zonas urbanas, apresentando-as como fator limitador do exercício do direito de propriedade (parte 2.1). Ainda, uma vez reconhecida a existência de um conflito entre direitos fundamentais, impende investigar se, subsiste a possibilidade de o direito individual de propriedade subjugar o direito difuso ao meio ambiente ecologicamente equilibrado, ou se, genericamente, não há prevalência de um direito sobre o outro, através da análise dos princípios em embate e do critério da ponderação para resolução de tal celeuma (parte 2.2).

\subsection{As Áreas de Preservação Permanente como Limitação ao Direito de Construir:}

As áreas de preservação permanente tem seu conceito, fundamentalmente, descrito no corpo do Código Florestal de $1965^{18}$ e, tendo em vista a sua funcionalidade e imprescindibilidade para a manutenção do equilíbrio ecológico, recebem do legislador o condão de espaços

17 As áreas de preservação permanente (APP's) constituem-se em uma das espécies de áreas especialmente protegidas pelo legislador e são essenciais para a preservação dos recursos hídricos, a paisagem, a diversidade biológica, bem como desempenham papel importante na proteção do solo, assegurando às populações humanas um meio ambiente capaz de garantir-lhes um mínimo de bem-estar. A Reserva Legal também é um espaço cuja proteção especial foi determinada pelo legislador constitucional, todavia, não se tratará no presente trabalho acerca de sua importância e das previsões legais a ela atinentes.

${ }^{18}$ No trabalho em curso não se adentrarão nas questões referentes à Reforma do Código Florestal, atendose, basicamente, ao conceito de APP e da aplicabilidade da lei em comento às zonas urbanas. 
ISSN 1981-3694

(DOI) $10.5902 / 198136947526$

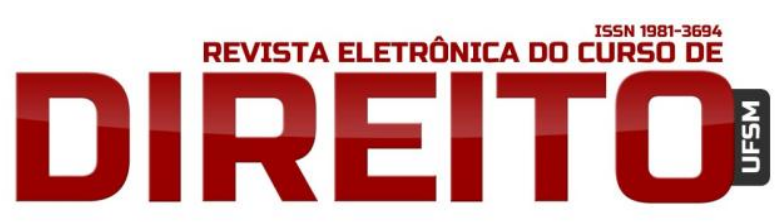

CONSTRUÇÕES EM ÁREAS DE PRESERVAÇÃO PERMANENTE E O CONFLITO ENTRE DIREITOS FUNDAMENTAIS

TATIÉLE CARDOSO MONTEIRO

especialmente protegidos. Tais áreas desempenham relevante papel na preservação dos recursos hídricos, da paisagem, da diversidade biológica (fauna e flora), na estabilidade geológica e na proteção dos solos, através da contenção de enchentes e da inviabilização de processos $\operatorname{erosivos}^{19}$. Nesse talante, mister se faz reconhecer que a sua importância prática está estritamente vinculada à qualidade de vida das populações, em especial, àquelas residentes nos espaços urbanos. Impõe-se admitir que a manutenção de tais espaços ambientais traduz-se no dever de todos de administrar os recursos naturais em prol da coletividade.

Partindo, portanto, da premissa de que espaços tais merecem uma atenção especial do legislador, a Constituição Federal, consoante já mencionado linhas acima, preconizou, como direito difuso e fundamental, aquele atinente à defesa do patrimônio ambiental e à garantia de um meio ambiente ecologicamente equilibrado, realçando a necessidade de que áreas que clamem por uma proteção mais incisiva, sejam preservadas às futuras gerações através de atos do Poder Público que visem à limitação de outros direitos sobre elas ${ }^{20}$. Em virtude disso, o direito de propriedade e, em consequência, a faculdade de edificar sobre áreas de preservação permanente devem se submeter às limitações legais e administrativas impostas pelo Poder Estatal.

Primeiramente, há que se destacar que a aplicabilidade do Código Florestal é absolutamente viável para os casos em questão ${ }^{21}$. Tendo sido inteiramente incorporada pela Lei Maior, em virtude de seus preceitos máximos de proteção ecológica, a referida Lei Federal traz previsões específicas, no que se refere às áreas especialmente protegidas em comento. Ademais, outorga, na esteira, inclusive, do que foi preconizado na Constituição Federal, a necessidade de que a regulamentação sobre tais áreas, em casos de incidência urbana, seja ditada pelo Poder Público, através da elaboração de Planos Diretores e de Leis de Uso do Solo²2.

\footnotetext{
${ }^{19}$ Artigos $3^{\circ}$, inciso II, e $4^{\circ}$, da Lei $12.651 / 12$ - correspondente às alterações já sancionadas no Código Florestal de 1965.

${ }^{20}$ Artigo 225 , § $1^{\circ}$, inciso III, da Constituição Federal.

${ }^{21}$ Existem discussões doutrinárias neste sentido. Alguns afirmam que a Resolução 369/2006 do CONAMA, veio a regulamentar a Lei do Parcelamento do Solo Urbano, no que tange aos limites métricos a serem observados nas áreas de preservação permanente no âmbito das cidades e, que, portanto, não seriam os limites alinhavados no Código Florestal os que prevaleceriam em tais casos. No presente trabalho, insta ponderar que não se adentrarão em minúcias no que tange, em específico, a regulamentação das APP's, mas tão apenas na sua importância para a manutenção do equilíbrio ambiental e seu caráter limitador frente ao direito de propriedade e, consequentemente, ao direito de construir. No mais, adota-se o posicionamento da regra do "in dubio pro ambiente", entendendo-se que aquela que for mais favorável à proteção ecológica deve ser aplicada.

${ }^{22}$ Artigo $4^{\circ}$, $\S \S 9^{\circ}$ e 10 , da Lei $12.651 / 12$.
} 
Neste talante, o advento do Estatuto das Cidades (Lei 10.257/01), regulamentando os artigos 182 e 183 da Constituição Federal e determinando, assim, a obrigatoriedade da fixação da temática da proteção ambiental ao ordenamento das cidades, estipulou a necessidade de efetivação de políticas urbanas para o resguardo, inclusive, em âmbito municipal, através da elaboração de Planos Diretores, de áreas de preservação permanente da intromissão privada. Ainda, a Lei de Uso e Parcelamento do Solo Urbano, neste mesmo norte, pretendeu, por meio da estipulação de áreas não edificáveis, a despeito do caráter essencialmente urbanístico, promover, especialmente, a proteção ecológica.

O que se observa, todavia, é que as previsões legislativas abarcadas pelos diplomas legais supramencionados possuem caráter suplementar, isto é, sobrevieram ao ordenamento jurídico, a fim de incrementar e ampliar o alcance das normas carreadas pelo Código Florestal. Em um âmbito mais restrito, evidentemente mais local, tais previsões devem se prestar a promover, em maior escala, a proteção das áreas de preservação permanente, inviabilizando a possibilidade de atuação humana sobre elas. Caso contrário, devem se submeter aos ditames trazidos pelo Código Florestal, vez que o escopo maior de tais preceitos é, justamente, garantir a todos um meio ambiente saudável, capaz de proporcionar qualidade de vida e bem-estar a toda coletividade.

Nesta senda, pode-se concluir que as áreas de preservação permanente se prestam, em larga medida, a limitar o exercício do direito de propriedade. Ao lado da necessidade de implementação da função socioambiental, as limitações legais e administrativas incorporadas no ordenamento jurídico, possuem o condão de resguardar as áreas de preservação permanente da atuação humana predatória. A despeito de, em casos específicos e estritamente regulamentados, se permitir a interferência privada em tais espaços, esta se trata da exceção ${ }^{23}$. A regra é, a todo custo, garantir que as áreas de preservação permanente sejam caracterizadas pela intangibilidade e pela não exploração.

Assim, ao que se verifica, inicialmente, o direito de construir em áreas de preservação permanente sucumbe frente à necessidade de garantir a sua perpetuação, não apenas em

Ressalta-se que, o § 10 , do artigo $4^{\circ}$, da Lei $12.651 / 12$, deixa claro que a existência de normas regulamentando o trato com as áreas de preservação permanente não excluem a viabilidade de aplicação dos preceitos carreados nos incisos do referido artigo, o que demonstra que, além de ter sido recepcionada integralmente pela Constituição Federal, serve de parâmetro para a aferição dos limites ali previstos.

${ }^{23} \mathrm{O}$ artigo $4^{\circ}$ do Código Florestal, com redação dada pela Medida Provisória $n^{\circ}$ 2.166-67/2001, prevê que, em casos de utilidade pública ou de interesses socioeconômicos, a vegetação das áreas de preservação permanente poderão ser suprimidas para darem lugar à construção de obras, dentre outros. A Resolução $369 / 2006$ do CONAMA veio, posteriormente, a regulamentar tais casos, em seu artigo $2^{\circ}$, incisos I e II. 
virtude de interesses urbanísticos, mas especial e principalmente, por motivos de manutenção do equilíbrio ecológico.

Cristalino, por conseguinte, o conflito existente entre os direitos fundamentais tratados no presente trabalho. Urge, em virtude disso, analisar se subsiste a possibilidade de conviverem, através de critérios de proporcionalidade, ou se devem excluir-se, a fim de serem integralmente implementados.

\subsection{Direitos Fundamentais em Conflito: a ponderação como uma proposta para solucionar tal embate}

Reiterando tudo que foi afirmado durante a construção deste singelo trabalho, verifica-se que o avanço humano desregrado em direção às cidades, em que pese diversas outras consequências que traz ${ }^{24}$, em muitos casos se dá de forma a atingir áreas de importância máxima para a manutenção do equilíbrio ecológico: as áreas de preservação permanente. Como espaços especialmente protegidos pelo legislador, em função, propriamente, de sua vital importância para o bioma, há que se reconhecer que, muitas vezes, operam como uma limitação de destaque a uma das faculdades do direito de propriedade, qual seja, o direito de construir.

O direito de construir, conforme já se aduziu linhas acima, encontra-se corporificado no direito de propriedade e, constitui-se, portanto, em um direito fundamental, protegido pela Constituição Federal. Não cabe aqui, por conseguinte, argumentar quanto ao caráter prevalente de tal direito. Assegurado a todos os cidadãos de forma equânime, a faculdade de edificar em área própria, encontra respaldo na liberdade de administrar a propriedade, bem como na necessidade de garantir à mesma o cumprimento de sua função social.

De outro lado, porém, encontra-se um direito fundamental de natureza difusa, diferentemente, em um primeiro momento, do direito individual de propriedade: o direito ao meio ambiente ecologicamente equilibrado. Pertencente a toda a coletividade, de forma indeterminada, tal direito, igualmente preconizado no bojo da Constituição Federal, tem como principal desiderato a proteção ambiental, a manutenção do equilíbrio e ecológico e, consequentemente, a qualidade de vida de todos os indivíduos.

24 Citam-se algumas: aumento do número de favelas, construções em áreas de risco, degradação ambiental, falta de saneamento básico para grande parcela da população, acúmulo de lixo, falta de planejamento urbano, etc. 
Nesta senda, chega-se a um impasse: o direito fundamental de propriedade, in casu, tratando-se aqui do direito de construir, vê-se vedado pelo direito fundamental ao meio ambiente ecologicamente equilibrado, no que tange às áreas de preservação permanente? Ao que parece, inicialmente, a resposta para tal questionamento é bastante relativa. Há, por óbvio, um claro conflito de direitos fundamentais e, em virtude disso, faz-se necessário aferir se o exercício de um pode ser totalmente restringido pelo outro.

Nesse diapasão, partindo do pressuposto que no caso em comento subsistem diversos princípios constitucionais englobando o tema, referentes tanto a um quanto ao outro direito, tais como o princípio do direito fundamental ao meio ambiente ecologicamente equilibrado, o princípio do desenvolvimento sustentável, o princípio da função socioambiental da propriedade, impende, preliminarmente, admitir que não se pode, de imediato, vedar o exercício do direito fundamental de propriedade em função do direito ambiental em liça.

A despeito das inúmeras limitações de ordem principiológica, legal e administrativa atinentes ao caso em apreço, a ponderação ${ }^{25}$ dos direitos fundamentais em conflito faz-se inexorável para a resolução do embate entre ambos.

Primeiramente, há que se atentar para o fato de que já se ultrapassou o conceito individualista da propriedade privada, a qual, além da função social, deve cumprir com a função ambiental. Ou seja, sucumbe perante o ordenamento jurídico a ideia de que a propriedade privada se presta tão somente a garantir ao seu proprietário vantagens de ordem econômica individual, devendo, em decorrência direta de tal ilação, adequar-se aos ditames legais atinentes à proteção ambiental.

Nessa esteira, o que se afere é que o direito difuso ao meio ambiente equilibrado prevalece frente ao direito individual de propriedade. A imprescindibilidade de manter-se 0 meio ambiente em condições adequadas para a vida humana traduz-se como corolário do princípio da dignidade da pessoa humana, admitindo-se, em um primeiro momento, a supremacia do interesse coletivo sobre o interesse individual. Porém, tal ilação deve ser administrada com cautela, uma vez que o patamar igualitário dos direitos fundamentais em conflito impõe tal medida.

\footnotetext{
${ }^{25} \mathrm{Na}$ esteira do que ensina Humberto Ávila, em sua obra Teoria dos Princípios: "A ponderação de bens consiste num método destinado a atribuir pesos a elementos que se entrelaçam, sem referência a pontos de vista materiais que orientem esse sopesamento. Fala-se, aqui e acolá, em ponderação de bens, de valores, de princípios, de fins, de interesses." E segue inferindo que "Quando se utiliza a expressão "ponderação", todos os elementos acima referidos (bens jurídicos, interesses e valores) são dignos de ser objeto de sopesamento."
} 
Admitindo-se, assim, que o critério da ponderação é uma das soluções para os casos de construções em áreas de preservação permanente, há que se referir que os meios perpetrados para o alcance do fim máximo em análise (manutenção do equilíbrio ecológico), devem ser gerenciados de forma minuciosa, atentando-se para os casos em que a supressão de tais espaços cedem frente a questões de utilidade pública de interesses estatais socioeconômicos. Não é, assim, regra absoluta, mas encontra-se tal direito fortemente limitado quando atinentes a áreas de preservação permanente.

Ademais, em se tratando de casos não inclusos nos supramencionados, a possibilidade de que se exerça o direito de propriedade em áreas de preservação permanente não pode ser irremediavelmente excluída. Há que se ter em mente que os direitos em confronto são constitucionalmente protegidos, sendo equivalentes quanto a sua importância e funcionalidade.

Neste sentido, interessante ressaltar o entendimento de Marcelo Sampaio Siqueira, em sua obra, o qual, tratando das limitações ao direito de construir impostas pela própria função social da propriedade, aduz que a ponderação deve reger o entendimento daquele que interpreta as leis e as aplica nos casos concretos:

A colisão de direitos, como por exemplo, a restrição ao direito de edificar com atendimento da função social da propriedade, abre a necessidade de uma ampla discussão acerca do limite ao seu exercício, devendo-se analisar o direito subjetivo e o interesse coletivo. Um dos métodos passíveis de utilização para resolver esse impasse é a análise da questão à luz da máxima da proporcionalidade ou da justa medida (...). O princípio da proporcionalidade encontra-se indiretamente positivado na Constituição de 1988 , art. $5^{\circ}$, $\S 2^{\circ}$, e confere ao hermeneuta o dever de interpretar o fato jurídico mediante um juízo de ponderação $(. . .)^{26}$.

Por conseguinte, a ponderação, seguindo, ainda o critério da proporcionalidade, permite que se vislumbre a possibilidade do exercício do direito de construir, quando existente a limitação inerente às áreas de preservação permanente. O sopesamento dos princípios e dos direitos em questão deve se dar de forma circunstancial, caso a caso, avaliando-se quão negativos podem ser os reflexos da deturpação de um direito em função de outro, viabilizando, por exemplo, ao proprietário, a possibilidade de corrigir ou, posteriormente, ressarcir ao meio ambiente pelos danos eventualmente causados ou que poderão vir a ser implementados ${ }^{27}$.

${ }^{26}$ SIQUEIRA, Marcelo Sampaio. Direito de Construir: Perfil Constitucional e Restrições. Curitiba: Juruá, 2012, p. 129.

${ }^{27}$ Mas isso é assunto para outro momento, não cabendo aqui, adentrar nesta discussão. 
Basta concluir, por ora, que o direito de construir, em que pese intensamente limitado nas zonas urbanas pelas áreas de preservação permanente, não está, de todo, impossibilitado ou inviabilizado. Há que se atentar que tal juízo de ponderação se presta a aferir se restrições tais ao direito de construir se mostram proporcionais, entre a perda do proprietário e o ganho da coletividade $^{28}$. Assim, respeitados 0 interesse coletivo e a possibilidade de compatibilizar 0 exercício de tal faculdade e a manutenção do equilíbrio ao proprietário, entende-se que através de critérios de ponderação e de proporcionalidade, tais direitos, em alguns casos, podem coexistir.

\section{CONCLUSÃO}

O êxodo rural experimentado desde meados do século XIX pela população brasileira culminou na urbanização de espaços territoriais diversos. Conforme dados do IBGE, há atualmente no Brasil cerca de 5.565 (cinco mil quinhentos e sessenta e cinco) municípios e, em muitos casos, o acelerado e desorganizado processo de urbanização operado, deu azo a inúmeros problemas estruturais e ambientais. Por outro lado, como consequência também desse processo de ocupação e estruturação das cidades, o desenvolvimento econômico do país foi incrementado. A indústria da construção civil, em específico em tais casos, sem dúvida alguma, é uma das hélices que movimentam a economia brasileira.

Entretanto, o século XX também foi palco de uma preocupação da sociedade, como um todo: o desenvolvimento econômico aliado à manutenção do equilíbrio ecológico. Nesse talante, emergiu no seio social questões relativas ao desenvolvimento sustentável e as atenções foram voltadas à necessidade de preservar o equilíbrio ambiental às futuras gerações, colocando em conflito diversos interesses dos indivíduos, uns de cunho individual, outros de cunho difuso e coletivo.

Neste clima, portanto, uma das celeumas jurídicas que se faz presente, desde então, diz respeito ao conflito existente entre o direito de construir e o direito ao meio ambiente ecologicamente equilibrado, quando o cenário de exercício daquele primeiro se dá nas denominadas áreas de preservação permanente.

${ }^{28}$ SIQUEIRA, Marcelo Sampaio. Direito de Construir: Perfil Constitucional e Restrições. Curitiba: Juruá, 2012, p. 129. 
0 presente trabalho intentou, na esteira desta dicotomia de direitos, abordar, primeiramente, as questões relativas ao caráter fundamental do direito de construir, como uma faculdade do direito de propriedade. Como se sabe, o direito de propriedade confere ao dono de um bem a possibilidade de usufruí-lo da forma como bem the convir, desde que respeitados os direitos de terceiros. Nesse norte, tem-se que o direito de construir consiste em uma forma de utilização de bens imóveis, vez que ao proprietário é conferido o direito de edificar em seus domínios.

Com um caráter prementemente individual, com a Constituição Federal de 1988, o legislador constituinte impingiu ao proprietário o dever de garantir à sua propriedade o cumprimento da função social, como forma de obtenção de proteção estatal para seus bens. E, conforme se observou, foi mais além: determinou que o exercício de tal direito se desse de forma consonante com a manutenção do equilíbrio ecológico, extirpando o caráter meramente individual do direito de propriedade e conferindo-lhe contornos mais sociais. Consolidou, assim, o direito ao meio ambiente saudável e equilibrado, da mesma forma, como um direito fundamental dos cidadãos, constitucionalmente assegurado, com natureza difusa e de obrigatoriedade geral.

Nesta senda, em um segundo momento, intentou-se demonstrar que este direito difuso deve servir de parâmetro de conduta para todos os cidadãos e, em considerando os espaços especialmente protegidos pelo legislador abordados no presente trabalho, deve se relevar que a qualidade de vida dos seres humanos está intrinsicamente relacionada à adequação do direito de construir a tal preceito.

Buscando, portanto, responder ao questionamento levantado, demonstrou-se a importância das áreas de preservação permanente e seu caráter limitador ao exercício do direito de construir. Através das restrições legais e administrativas existentes, no que tange à intromissão humana em tais áreas, foi possível inferir que, em virtude de sua importância para a manutenção do equilíbrio ecológico e, em consequência, à qualidade de vida da coletividade, o impasse entre a viabilidade de o proprietário de uma determinada área como essa erguer construções, alterando e suprimindo as suas características, é bastante restrita.

Entretanto, uma vez que se tratam ambos de direitos fundamentais, a vedação à realização de empreendimentos nas áreas de proteção permanente, em que pese tratar-se da regra, na maioria das vezes, bem como a despeito de suportar exceções previamente autorizadas, não pode ser vista de forma absoluta. Sendo assim, intentando elucidar a questão arguida, observou-se, ainda que de forma bastante incipiente, que a ponderação dos princípios e 
ISSN 1981-3694

(DOI) $10.5902 / 198136947526$

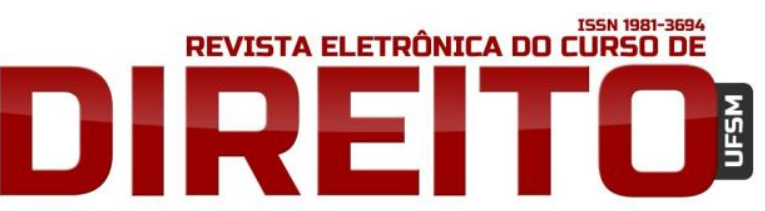

CONSTRUÇÕES EM ÁREAS DE PRESERVAÇÃO PERMANENTE E O CONFLITO ENTRE DIREITOS FUNDAMENTAIS

TATIÉLE CARDOSO MONTEIRO

direitos em conflito deve primar pela resolução da celeuma sob análise, havendo que, nos casos práticos, serem analisados, criteriosamente, os pesos e medidas de cada um dos direitos em confronto.

Por conseguinte, através da confecção do presente trabalho, o qual restou construído a partir de algum embasamento teórico e de pesquisas de caráter bastante preliminar, sem intentar esgotar o tema e sem a presunção de abordar todas as questões relativas a tamanho imbróglio, conclui-se que, haja vista a inegável e relevante importância que as áreas de preservação permanente nas zonas urbanas assumem perante a manutenção do equilíbrio ecológico, como regra geral, a prevalência do direito fundamental ao meio ambiente saudável e equilibrado face ao direito individual de propriedade é indiscutível e deve, sem dúvida alguma, ser sempre o norteador da solução de conflitos de tal natureza. Todavia, reitera-se que o caráter também fundamental do direito de construir deve ser devidamente sopesado, de forma a que se averigue a possibilidade de que tal direito não fique por inteiro limitado.

O bom senso daquele que decidirá a questão deverá, portanto, servir de respaldo para a ponderação adequada dos valores em conflito, procedendo-se, quando possível, à adequação do exercício de um em prol da efetivação de outro. Em suma, em casos específicos, os quais não cabem aqui referir ou analisar, poderá o hermeneuta se utilizar da máxima "nem tanto aos céus, nem tanto ao mar", em outros, contudo, a supremacia do interesse coletivo deverá orientar a resolução do conflito.

\section{REFERÊNCIAS}

ÁVILA, Humberto. Teoria dos Princípios: da definição à aplicação dos princípios jurídicos. 12 . Ed, ampliada. São Paulo: Malheiros, 2011.

Brasil. Código Civil (2002). Lei 10.406/02: Institui o Código Civil: promulgada em 10 de janeiro de 2002. Disponível em <http://www.planalto.gov.br/ccivil_03/leis/2002/L10406.htm>. Acesso em: 20 Dez. 2012.

Brasil. Código Florestal (1965). Lei 4.771: Institui o Novo Código Forestal: promulgada em 15 de setembro de 1965. Disponível em <http://www.planalto.gov.br/ccivil_03/leis/L4771.htm>. Acesso em: 20 Dez. 2012.

Brasil. Constituição (1988). Constituição da República Federativa do Brasil: promulgada em 5 de outubro de 1988: atualizada até a Emenda Constitucional n. 68, de 21-12-2011. 7. ed. São Paulo: Saraiva, 2012. 
ISSN 1981-3694

(DOI) $10.5902 / 198136947526$

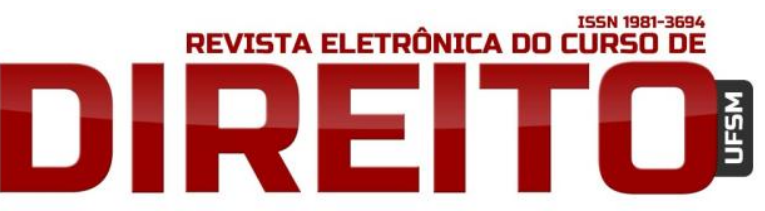

CONSTRUÇÕES EM ÁREAS DE PRESERVACC̃̃O PERMANENTE E O CONFLITO ENTRE DIREITOS FUNDAMENTAIS

TATIÉLE CARDOSO MONTEIRO

Brasil. Lei Federal (2012). Lei 12.651: Dispõe sobre a proteção da vegetação nativa; altera as Leis $\mathrm{n}^{\mathrm{os}}$ 6.938, de 31 de agosto de 1981, 9.393, de 19 de dezembro de 1996, e 11.428, de 22 de dezembro de 2006; revoga as Leis nos 4.771, de 15 de setembro de 1965, e 7.754, de 14 de abril de 1989, e a Medida Provisória no 2.166-67, de 24 de agosto de 2001; e dá outras providências: promulgada em 25 de maio de 2012. Disponível em <http://www.planalto.gov.br/ccivil_03/_Ato2011-2014/2012/Lei/L12651.htm>. Acesso em: 20 Dez. 2012.

INFORMATIVO ECONÔMICO: Construção Civil: Desempenho e Perspectivas. Disponível em: <http://www.cbicdados.com.br/media/anexos/05_Balanco_2011.pdf>. Acesso em: 22 Set. 2012.

INSTITUTO BRASILEIRO DE GEOGRAFIA E ESTATÍ́STICA. Pesquisa Anual da Indústria da Construção. Instituto Brasileiro de Geografia e Estatística, 2012. Disponível em:

<http://www.ibge.gov.br/home/estatistica/economia/industria/paic/2010/default.shtm >. Acesso em: 22 Set. 2012.

FARIAS, Cristiano Chaves de; ROSENVALD, Nelson. Direitos Reais. 7. ed. Rio de Janeiro: Lumen Juris, 2011.

MEIRELLES, Hely Lopes. Direito de Construir. 10. ed. São Paulo: Malheiros, 2011.

SIQUEIRA, Marcelo Sampaio. Direito de Construir: Perfil Constitucional e Restrições. Curitiba: Juruá, 2012.

Recebido em: 20.12.2012

Revisado em: 26.02.2013

Aprovado em: 08.03.2013 